\title{
Endosymbiotic bacteria Wolbachia in Siberian populations of Acrididae grasshopper (Orthoptera)
}

\author{
A. Tikhomirova ${ }^{1 *}$, M. Yudina ${ }^{1,2}$, G. Yurlova ${ }^{2}$, R. Bykov ${ }^{2}$, A. Bugrov ${ }^{1,3}$, Yu. Ilinsky ${ }^{1,2}$ \\ ${ }^{1}$ Novosibirsk State University, Novosibirsk, Russia \\ ${ }^{2}$ Institute of Cytology and Genetics SB RAS, Novosibirsk, Russia \\ ${ }^{3}$ Institute of Systematics and Ecology of Animals SB RAS, Novosibirsk, Russia \\ *e-mail:a.tikhomirova9@g.nsu.ru
}

Key words: Acrididae, grasshopper, population, endosymbiont, Wolbachia, Siberia

Motivation and Aim: Wolbachia are maternally inherited symbionts that infect a wide range of arthropods. Wolbachia may influence on host biology by mutualistic or parasitic ways. For some insect taxa there are no data on Wolbachia diversity and its effects on the host. In this work we address to one of those taxa - family Acrididae. This family contain about 9000 species [1] but very few of them were studied on Wolbachia. We aim to characterize prevalence and genetic diversity of Wolbachia in Siberian populations of Acrididae.

Methods and Algorithms: Total collection includes 339 samples of 17 species from 10 genera: Arcyptera, Bohemanella, Bryodema, Chorthippus, Gomphocerippus, Oedaleus, Ognevia, Omocestus, Podisma, Stauroderus. Insects were collected from Novosibirsk and Irkutsk provinces, Altai Republic and Altai Krai. The DNA extraction was individually performed from legs and/or abdomens for each specimen. Wolbachia infection status was determined by PCR with primers specific to coxA and wsp Wolbachia genes. Genetic diversity of Wolbachia isolates was determined by PCR with primers to five Wolbachia loci according to the multilocus sequence typing (MLST) protocol [2]. Results: We found Wolbachia infection in 16 of 17 studied Acrididae species. The infection rates of some hosts were high. For instance, Chorthippus biguttulus population of Novosibirsk province was infected with the rate of $91.0 \pm 2.2 \%$. New Wolbachia haplotypes were found in grasshopper hosts.

Conclusion: This is the first report on Wolbachia infection in 15 species of Acrididae. We demonstrate high Wolbachia infection rate in Siberian grasshopper's populations and revealed new haplotypes of bacteria.

Acknowledgements: Supported by the RFBR (18-316-00099, 16-04-00980, 18-04-00192).

References

1. Richards O.W., Davies R.G. (2013) Imms' General Textbook of Entomology: Vol. 2: Classification and Biology. Springer Science Business Media.

2. Baldo L. et al. (2006) Multilocus sequence typing system for the endosymbiont Wolbachia pipientis. Applied Environmental Microbiology. 72(11):7098-7110. 